\title{
Uso da haptoglobina como marcador biológico para a detecção de diarreia em bezerras Holandesas
}

Karen Nascimento da Silva ${ }^{[a]^{*}}$, Jean Silva Ramos ${ }^{[a]}$, Karina Medici Madureira2 ${ }^{[b]}$ José Eugênio Guimarães ${ }^{[b]}$, Camila Cecília Martin ${ }^{[a]}$, Sylvia Marquart Fontes Novo[a], Juliana França dos Reis Costa ${ }^{[a]}$, Camila Costa Baccili[a], Natália Sobreira Basqueira ${ }^{[a]}$, Viviani Gomes[a]

\footnotetext{
[a] Faculdade de Medicina Veterinária e Zootecnia, Universidade de São Paulo (USP), São Paulo, SP, Brasil

${ }^{[b]}$ Escola de Medicina Veterinária e Zootecnia, Universidade Federal da Bahia (UFBA), Salvador, BA, Brasil
}

*Autor correspondente

e-mail: karen.n.silva@hotmail.com

\section{Resumo}

A haptoglobina (Hp) é uma proteína de fase aguda que tem sido utilizada como biomarcador para o monitoramento da saúde em bovinos, entretanto, a sua viabilidade para a detecção de doenças na criação de bezerras tem sido pobremente explorada. $\mathrm{O}$ objetivo deste estudo foi avaliar o uso da Hp como biomarcador para a detecção de inflamação intestinal em bezerras Holandesas. Para tanto, foram utilizadas 71 bezerras com idade entre 11 e 28 dias, provenientes de duas propriedades leiteiras de alta produção localizadas em São Paulo. As bezerras foram triadas pelo escore de fezes padronizado pela Universidade de Wiscosin-Madison: escore 0 - consistência firme, escore 1 - consistência pastosa ou semi-formada, escore 2- consistência pastosa com maior quantidade de água e conteúdo fecal aderido ao períneo, e escore 3 - fezes líquidas com conteúdo fecal aderido ao períneo. Bezerras que apresentaram outras doenças não foram incluídas neste estudo. A análise de Hp foi analisada por técnica espectrofotométrica. Os animais que apresentaram escore fecal 0 e 1 foram considerados negativos $62 \%(44 / 71)$ e os escores 2 e 3 , positivos $38 \%$ (27/71). As bezerras positivas (Mediana = 1,52 mg/dL; Mín. e Máx. 0,47 - 40,5 mg/dL) apresentaram valor mediano semelhante às negativas (1,43 mg/dL; Mín. e Máx. 0,38 - 4,5 mg/dL); entretanto, foi possível detectar diferenças na concentração de Hp entre os escores ( $\mathrm{P}=0,031$; Kruskal Wallis). Bezerras que apresentaram escore fecal 3 apresentaram maiores valores de Hp sérica (Mediana = 4,07 mg/dL; Mín. e Máx. 1,62 - 40,5 mg/dL), quando comparadas àquelas com escore fecal 0 (Mediana $=1,18 \mathrm{mg} / \mathrm{dL}$; v. máx e mín $=0,78-2,92 \mathrm{mg} / \mathrm{dL})(\mathrm{P}=0,007)$. As bezerras com escore fecal 2 provavelmente possuem processo inflamatório localizado, enquanto que aquelas com escore fecal 3 apresentaram inflamação sistêmica caracterizada por maiores concentrações de Hp. 